\title{
MENTAL HEALTH SUPPORT IN THE PERINATAL PERIOD FOR WOMEN WITH A PERSONALITY DISORDER DIAGNOSIS: A QUALITATIVE STUDY OF WOMEN'S EXPERIENCES
}

\author{
Alice Zacharia, MSc, Billie Lever Taylor, DClinPsy, \\ Angela Sweeney, PhD, Nicola Morant, PhD, \\ Louise M. Howard, PhD, MRCP, and \\ Sonia Johnson, MRCPSYCH, DM
}

\begin{abstract}
Women who receive a diagnosis of personality disorder may face particular challenges in the context of having a baby. However, this area has received little attention. This study aimed to qualitatively explore experiences of mental health support during the perinatal period in a group of mothers who self-reported having a personality disorder diagnosis. Semistructured interviews were conducted with 12 women who received mental health support during the perinatal period. These data were analyzed thematically. Key themes related to women feeling judged to be unfit mothers; not feeling heard or understood by services; feeling that services struggled with the complexity of their needs; valuing specialist support to cope with their struggles in motherhood; and valuing professional relationships that resembled real-life friendships. Our findings raise questions about how best to provide support to this group of women and about the use and consequences of the diagnosis of personality disorder among new mothers.
\end{abstract}

Keywords: perinatal, personality disorder, mental health, qualitative, women, mothers

\footnotetext{
From Division of Psychiatry, University College London, London, UK (A. Z., B. L. T., N. M., S. J.); Population Health Research Institute, St. George's University of London, London, UK (A. S.); and Section of Women's Mental Health, Institute of Psychiatry, Psychology, and Neuroscience, King's College London, London, UK (L. M. H.).

This article summarizes independent research funded by the National Institute for Health Research (NIHR) under its PGfAR Programme (Grant Reference Number RP-PG-1210-12002). The views expressed are those of the authors and not necessarily those of the NIHR or the Department of Health and Social Care.

S.J. is supported by the NIHR Mental Health Research Policy Unit, the NIHR Collaboration for Leadership in Applied Health Research and Care (CLAHRC) North Thames, and the UCLH Biomedical Research Centre. L.M.H. was supported by a National Institute for Health Research (NIHR) Research Professorship (NIHR-RP-R32-011). She is now partly supported by the South London and Maudsley NHS Foundation Trust/King's College London Biomedical Research Centre and is also supported by the NIHR Mental Health Research Policy Unit. A.S. is funded by a NIHR Post-Doctoral Fellowship.

The authors are very grateful indeed for the advice and support received from the Perinatal Service User and Carer Advisory Group, and from the wider ESMI study team. The study team would also like to thank all the women who gave up their time to take part in the study.

Address correspondence to Billie Lever Taylor, DClinPsy, Division of Psychiatry, University College London, Maple House, 149 Tottenham Court Road, London, W1T 7NF, UK. E-mail: billie.taylor@ucl.ac.uk
} 
The perinatal period, which spans from conception to 1 year after birth, is a challenging time for many women. An estimated $20 \%$ of women experience mental health problems during this time (Russell, Ashley, Chan, Gibson, \& Jones, 2017). Research into perinatal mental health has largely focused on postnatal depression (Howard et al., 2014; Stein et al., 2014). One group of mothers who have received very little attention in research or service development are those who receive a diagnosis of personality disorder. The usefulness and psychometric robustness of personality disorder diagnoses continue to be debated (Kim \& Tyrer, 2010), as does the extent to which conditions such as "borderline personality disorder" (BPD) should be seen as enduring interpersonal difficulties, or as the sequelae of complex trauma (Kulkarni, 2017). In population surveys, "personality disorders" have been estimated to affect $4.4 \%$ of the population in Britain (Coid, Yang, Tyrer, Roberts, \& Ullrich, 2006), while the prevalence of "disordered personality traits" was estimated to be $16.2 \%$ in a sample of pregnant women in London (Crowley et al., 2020).

It has been argued that women with a personality disorder diagnosis may find pregnancy and early motherhood more challenging than other women (Börjesson, Ruppert, \& Bågedahl-Strindlund, 2005; Conroy et al., 2012). Mothers with diagnoses of BPD have been found to respond less sensitively to their infants (Newman, Stevenson, Bergman, \& Boyce, 2007) and to have difficulty identifying their infants' emotional states (Petfield, Startup, Droscher, \& Cartwright-Hatton, 2015). Poorer emotional and mental health outcomes have been reported for children of mothers with diagnoses of BPD (Eyden, Winsper, Wolke, Broome, \& MacCallum, 2016; Petfield et al., 2015). New mothers with diagnoses of personality disorders are thought to receive less social and financial support than other mothers (Eyden et al., 2016), which may contribute to difficulties in looking after their children. It has been noted that social services frequently raise child protection concerns in relation to this population (Stanley \& Penhale, 1999).

Having a personality disorder diagnosis can also be associated with difficulties with accessing, receiving, and engaging with mental health support (Jinks, McMurran, \& Huband, 2012; Wilson, Weaver, Michelson, \& Day, 2018). The diagnostic label of personality disorder has been criticized for being highly stigmatizing (Aviram, Brodsky, \& Stanley, 2006; NewtonHowes, Weaver, \& Tyrer, 2008), with evidence suggesting that clinicians may judge people with personality disorder diagnoses more negatively than those with other diagnoses (Lewis \& Appleby, 1988; Markham \& Trower, 2010). In a qualitative study of mothers assessed to have a personality disorder with children (aged 3-11 years) showing behavioral and/or emotional difficulties, women believed that clinicians assumed their personality disorder diagnosis automatically meant they would be a "bad parent," and the women feared being seen as uncooperative if they did not acquiesce to professional advice and intervention (Wilson et al., 2018). It has been argued that, when applied to mothers, this diagnosis may also have the effect of preventing access to certain types of treatment that are deemed unsuitable for people with this diagnosis (Stanley \& Penhale, 1999).

While these findings suggest that mothers diagnosed with personality disorders may experience complex emotional and social difficulties for which 
they struggle to access appropriate support, to our knowledge no studies have explored experiences of mental health support among perinatal women with this diagnosis. However, the perinatal period is thought to be a time associated with distinctive risks and difficulties that are different from other periods in women's lives (Brockington, 2004).

In this study, we therefore aimed to explore views and experiences of support during the perinatal period in a group of mothers with a diagnosis of personality disorder. In England, this study is particularly timely because NHS England (2019) has stated in its Long Term Plan that it aims to improve access to perinatal mental health care, and in particular to improve access to evidence-based treatment for women with personality disorder diagnoses in the perinatal period.

\section{METHODS}

This study was part of the wider qualitative Stakeholders' Views and Experiences of Perinatal Mental Health Care (STACEY) study, which sought to explore experiences of services across England treating women with a range of perinatal mental health difficulties. STACEY was itself part of a larger mixedmethods project: the Effectiveness of Services for Mothers with Mental Illness (https://www.kcl.ac.uk/ioppn/depts/hspr/research/ceph/wmh/projects/a-z/ esmi).

\section{PARTICIPANTS}

Sampling for the wider STACEY study was purposive to gain a broad range of participants with respect to age, ethnicity, sociodemographic factors, mental health diagnosis, and type(s) of services used. Women who were no longer their child's main caregiver as well as women who still cared for their child were included.

Twelve women were selected from the wider STACEY study data set (of 52 women) because they had all self-reported having a diagnosis of a personality disorder. Twelve would usually be considered at the lower end of a suitable sample size for qualitative work if the sample is relatively homogeneous (Guest, Bunce, \& Johnson, 2006). These 12 women were recruited from six diverse NHS health care providers in England. Other inclusion criteria required that women were age 16 years or over, were English language speakers, had accessed support for their mental health during or after their most recent pregnancy, and were 6-9 months postpartum at the time of interview (so that they had some time postbirth to reflect on their experiences of support during pregnancy and in the early postnatal period). Individuals lacking capacity to consent were not invited to participate. NHS ethical approval was obtained.

\section{RECRUITMENT}

Eligible women (who met purposive sampling criteria) were provided with a study information sheet by a clinician within their mental health team. 
Clinicians passed the contact details of those expressing an interest in participating to the research team, with the women's permission. A researcher contacted interested women to discuss the study further and arrange an interview for those who provided written consent. All participants received $£ 15$ as a token of thanks. Because researchers were only informed of women who were interested in participating, it is not possible to determine how many women declined to take part.

\section{DATA COLLECTION}

A topic guide was developed by the research team. This was informed by input from a perinatal service user and caregiver advisory panel and by the existing literature. It was piloted with service users and members of the advisory panel, and then adapted before data collection took place. Semistructured interviews were conducted between June 2015 and March 2017 by the second author (B.L.T.). Women were asked about a number of topics, including their experience of accessing services for mental health problems in the perinatal period; information, choice, and involvement in decision making; views and experiences of service delivery and perceived gaps/shortcomings; communication between services; family inclusion; and the quality of therapeutic relationships. Interviews lasted approximately one hour, and were audio-recorded, transcribed, and anonymized. Reflective notes were made immediately following the interview by the interviewer summarizing the content of the interview and highlighting particularly striking content at an early stage. Data pertaining to demographic characteristics of the participants were also collected.

\section{DATA ANALYSIS}

A thematic analysis of the interview transcripts was conducted by the first author (A.Z.). This is a rigorous method that can be used to identify and analyze repeated patterns of meaning within textual data (Braun \& Clarke, 2006). Interview transcripts were imported into NVivo 11, enabling the systematic analysis of this rich data set. Due to the exploratory nature of our research question, lack of existing literature on this topic, and our aim to focus on participants' experiences, a primarily inductive approach was taken to identify themes within the data. The entire data set was read, and initial thoughts about the interviews were noted. Interview transcripts were then coded line-by-line to generate initial codes. Relationships between codes were explored, so that codes were organized into a hierarchical structure and higher level themes could be identified. This was an iterative process; interviews were reread and recoded repeatedly to ensure that a comprehensive coding structure was developed. A second researcher (a Master's student) coded four interviews and discussed initial codes with the first author. These two researchers and other authors subsequently discussed emerging themes, and this was used to inform a shared understanding of the data.

A critical realist approach was adopted; the words and meanings used by participants were taken at face value, while acknowledging their broad social context and the influence of researcher perspectives throughout the 
research process. Interviews were conducted by the second author (B.L.T.), who is herself a mother, as well as a researcher and clinical psychologist, and was visibly pregnant during some of the interviews, which may have influenced how participants responded to her. A.Z. was a student studying for a Master's degree in Clinical Mental Health Sciences at the time of the study, and was working part time in a community mental health team specializing in supporting individuals diagnosed with a personality disorder. Her existing knowledge and experience of working with people diagnosed with a personality disorder, as well as her interactions with the clinicians who work with this population, may have influenced her expectations about the participants in the present study. The collaborative analytic processes described above allowed the research team to reflect on these factors and ensured that different perspectives were brought into the analytic process, thus increasing the validity of findings (Forman \& Damschroder, 2007).

\section{RESULTS}

\section{PARTICIPANT CHARACTERISTICS}

Participant characteristics are shown in Table 1. Just over half of the mothers $(n=7)$ were White British. Five mothers self-reported a diagnosis of BPD/ emotionally unstable personality disorder, while seven did not specify a type of personality disorder diagnosis. Six mothers self-reported having a diagnosis of depression as well as their personality disorder diagnosis, and four of these six also self-reported diagnoses of bipolar disorder, posttraumatic stress disorder (PTSD), anxiety, and postpartum psychosis. Mothers had received support from a wide range of professionals and services in the perinatal period. A brief description of these services is provided in Table 2. Most mothers used more than one service, as indicated in Table 1.

Ten of the 12 mothers received input from social services, which was conspicuously high compared to the broader STACEY project sample. Four of the mothers interviewed did not have custody of their child at the time of interview, and one additional mother was undergoing a parenting assessment. Three other mothers had children subject to a child protection plan. Such factors may have influenced women's accounts and perceptions of their experiences.

\section{QUALITATIVE FINDINGS}

Our analysis produced the following five themes: (a) "Feeling judged to be an unfit mother"; (b) "Difficulties in feeling heard or understood"; (c) "Services struggle with the complexity of mothers' needs"; (d) "Mothers value specialist support to cope with their struggles in motherhood"; and (e) "Valuing professional relationships resembling real-life friendships." For many of these women, complex and difficult social circumstances provided the backdrop to their accounts and experiences. Several of our respondents described or referred to relationship conflict, domestic violence, sexual abuse, substance misuse, trauma, and social services involvement themselves as children. 
TABLE 1. Participant Characteristics

\begin{tabular}{|c|c|}
\hline Characteristic & $n$ \\
\hline \multicolumn{2}{|l|}{ Ethnicity } \\
\hline White British & 7 \\
\hline White other & 2 \\
\hline Black African & 1 \\
\hline Black Caribbean & 2 \\
\hline \multicolumn{2}{|l|}{ Location } \\
\hline London & 5 \\
\hline South of England & 5 \\
\hline North of England & 2 \\
\hline \multicolumn{2}{|l|}{ Age (years) } \\
\hline 25 or under & 6 \\
\hline $26-35$ & 2 \\
\hline $36-45$ & 4 \\
\hline Mean age & 29.4 \\
\hline Age range & $19-42$ \\
\hline \multicolumn{2}{|l|}{ Self-described diagnoses } \\
\hline Personality disorder & 12 \\
\hline Emotionally unstable personality disorder/BPD & 5 \\
\hline Type of personality disorder not specified by participant & 7 \\
\hline Depression & 6 \\
\hline Anxiety disorder & 2 \\
\hline Bipolar disorder & 1 \\
\hline PTSD & 1 \\
\hline Postpartum psychosis & 1 \\
\hline \multicolumn{2}{|l|}{ Highest educational level } \\
\hline No formal qualifications & 4 \\
\hline GCSEs & 2 \\
\hline NVQ & 2 \\
\hline A-levels or equivalent & 2 \\
\hline Bachelor's degree & 2 \\
\hline \multicolumn{2}{|l|}{ Marital status } \\
\hline Married/cohabiting & 5 \\
\hline Single/separated & 7 \\
\hline \multicolumn{2}{|l|}{ Number of children } \\
\hline 1 & 7 \\
\hline 2 & 1 \\
\hline $3+$ & 4 \\
\hline \multicolumn{2}{|l|}{ Services used by mothers } \\
\hline Acute psychiatric inpatient ward & 3 \\
\hline Mother and baby unit (MBU) & 1 \\
\hline Specialist perinatal community mental health team & 5 \\
\hline Parent-infant team & 5 \\
\hline Specialist midwife/health visitor & 5 \\
\hline Crisis resolution team & 4 \\
\hline Personality disorder/complex needs team & 4 \\
\hline Community mental health team/recovery team & 6 \\
\hline
\end{tabular}

Note. PTSD = posttraumatic stress disorder; GCSE = General Certificate of Secondary Education; NVQ = National Vocational Qualification. 
TABLE 2. Description of Services

\begin{tabular}{|c|c|c|}
\hline $\begin{array}{l}\text { Specialist perinatal or } \\
\text { nonperinatal service }\end{array}$ & Type of service & Brief description \\
\hline \multirow[t]{4}{*}{ Specialist perinatal } & Mother and Baby Unit (MBU) & $\begin{array}{l}\text { Specialist inpatient unit where women with acute } \\
\text { mental health difficulties are admitted with their } \\
\text { babies }\end{array}$ \\
\hline & $\begin{array}{l}\text { Specialist perinatal community } \\
\text { mental health team }\end{array}$ & $\begin{array}{l}\text { Multidisciplinary teams that treat perinatal women } \\
\text { in the community with moderate to severe mental } \\
\text { health difficulties. Treatment is usually for up to } 1 \\
\text { year postbirth. }\end{array}$ \\
\hline & Specialist health visitors/midwives & $\begin{array}{l}\text { Health visitors and midwives with extra training to } \\
\text { enable them to offer support to women with mental } \\
\text { health difficulties }\end{array}$ \\
\hline & Parent-infant team & $\begin{array}{l}\text { Teams that focus on supporting the bond between } \\
\text { parent and baby }\end{array}$ \\
\hline \multirow[t]{4}{*}{ Nonperinatal } & General acute psychiatric ward & $\begin{array}{l}\text { General psychiatric hospitals for adults with mental } \\
\text { health difficulties where women are admitted. Babies } \\
\text { cannot be admitted to these wards. }\end{array}$ \\
\hline & Crisis resolution team & $\begin{array}{l}\text { Generic multidisciplinary teams that offer short-term } \\
\text { intensive home treatment to people experiencing an } \\
\text { acute mental health crisis }\end{array}$ \\
\hline & Community mental health team & $\begin{array}{l}\text { Generic multidisciplinary teams that treat adults with a } \\
\text { range of moderate to severe mental health difficulties }\end{array}$ \\
\hline & $\begin{array}{l}\text { Personality disorder or complex } \\
\text { needs teams }\end{array}$ & $\begin{array}{l}\text { Specialist services that offer targeted treatments } \\
\text { to people with personality disorders, such as } \\
\text { mentalization-based therapy, emotional skills groups, } \\
\text { and dialectical-behavioral therapy }\end{array}$ \\
\hline
\end{tabular}

Feeling Judged to Be an Unfit Mother. Many mothers said that, during pregnancy and after having their baby, they encountered professionals-health visitors, midwives, and social workers, as well as mental health professionalswhom they felt to be judgmental. Comments and actions by professionals communicated to these women that clinicians assumed they were unfit mothers. This judgment seemed at times to relate specifically to the stigma associated with personality disorders; some mothers felt that staff believed that you cannot be a good parent if you have a personality disorder diagnosis.

Just because like I've got a label in my [medical record] which says borderline, that doesn't mean that like I'm suicidal, I'm going to throw my baby off the bridge, but like that's how I got treated ...

... I always found it really, like, really horrible when they suggested that I'm a danger to my child. It was always like I could not open up.... And that happened with the doctor at the hospital, the health visitor, and the assessment at the [personality disorder service], these three. (Mother 2)

Some women expressed doubts about their abilities as mothers and difficult, ambivalent feelings toward their babies. However, several also described how having a baby had incentivized them to try to overcome their difficult experiences. But they said that, in their view, professionals had not acknowledged this and instead judged them solely on events from their past. 
Them workers, they was going by the report that you came in the door [with], not the change that you've done in your life. Not the remarkable change. ... You see when you have a bad past, it follows you for the rest of your life. (Mother 1)

Mothers sometimes felt they were constantly under observation and scrutiny. They felt this implied they were seen as a danger to their child, and said it had the effect of worsening their mental health.

I've just had a baby, my partner is sitting next to me, and, you know, I've got somebody staring at me 24 hours. I hate being stared at. ... And I think if I was going to top myself, that probably would be the time, you know, because I hated it so much. (Mother 4)

Difficulties in Feeling Heard or Understood. Several mothers described not feeling heard or understood by professionals. They felt that they should have been able to access mental health support before reaching a crisis point, and they described frustration around this. Several mothers suggested that their outcomes would have been better if they had received support earlier. Some felt that because their present struggles were sometimes not as dramatic as particularly difficult periods in their past, they were not taken as seriously as they should have been. One mother (Mother 8), who later lost custody of her baby, had wanted an admission to a specialist mother and baby unit (MBU) but said she was told she was "not ill enough for it." There were also concerns that professionals would only really listen to them if they self-harmed or were suicidal. When they refrained from these behaviors, in some case for the sake of their babies and to present as competent mothers, they struggled to communicate their distress to staff and found that they did not get the support that they needed.

What is it going to take for me to get recognized and say I need help? Do I really need to jump off a car park roof to get help? Do I really need to slash my wrists, keep taking overdoses, have my child taken off of me? What do I need to do to be heard? (Mother 6)

You have to put on this great face and paint this picture a certain way. And I think underneath it all I could have done with help a helluva lot earlier... . Because I hadn't self-harmed again or ended up in hospital, I wasn't put in any sort of ... That's more of a punishment, you know, rather than a "well done." (Mother 8)

Once they did access support, mothers felt that they could not be honest about the extent of their problems. Several mothers said that they had thought they could be honest with professionals, but subsequently regretted it when they felt it was used against them-for example, by the involvement of social services and sometimes the removal of the child from the mother's custody. For some mothers, their experience taught them that they should never have opened up about their struggles. 
[If I went back in time] I would never, ever open my gob to anybody in NHS about how I felt. (Mother 4)

Several mothers described feeling caught in "Catch-22" situations (Mother 7): They feared telling professionals too much in case it was used against them to take their child away, but if they did not open up enough, they were reprimanded for not working with professionals. These mothers wanted to express their frustration when support felt inadequate, but they feared being seen as aggressive or deteriorating.

You want to talk to people, but everything you're doing, you're trying to work out what's going to happen around that. So what's going to happen next? Are they going to come along and take my baby away? (Mother 8)

I felt like a failure, and I thought that if they think I'm a failure, then they'll take the kids away from me. So I thought, no, I'm fine, I'll get over this, this is just a little glitch. (Mother 3)

Mothers often had clear ideas about the sort of support they felt they needed, which was sometimes at odds with professionals' recommendations. This led some mothers to feel like their preferences and concerns were dismissed by staff. This often related to medication, which several mothers felt strongly opposed to taking, sometimes because they were pregnant or breastfeeding. Some mothers felt that staff were pushing them to take medication, possibly as a way of dealing with them quickly, without listening to their concerns or taking the time to consider the broader social and psychological factors that had led them to this point.

[The perinatal psychiatrist] just kept saying to me medication, medication, this is what's going to help you. Now, my mum has nonalcoholic-related liver disease through taking medication, and with my anxiety I'm petrified I'm going to end up that way. I expressed my fears and concerns to this doctor and her response to me was, "Well you're not going to get better if you don't take the medication. Just take it and man up." (Mother 6)

However, some mothers had experiences of professionals involving them effectively in decisions relating to their support. These mothers valued being given information about the options that were available to them and subsequently being given a choice.

I really liked [my specialist perinatal therapist]. So she, basically like, gave me ... let me make decisions much more of like, what do I need right now. So that was really good. (Mother 2)

Services Struggle With the Complexity of Mothers' Needs. Many mothers had multiple and intersecting therapeutic and support needs, with long histories of mental distress, trauma, difficult social circumstances, and input from many different services. Some mothers felt that staff were unable to deal with the 
complexity of their situations. This seemed particularly true of generic or nonperinatal mental health services.

I was always talking to anyone who would listen, and I'll be sharing all my stress and pains with them. And they would just listen and maybe sympathize, but only rarely was I speaking to the right person who could actually do something about it. (Mother 9)

Specifically, some mothers felt that professionals did not know how to deal with women diagnosed with a personality disorder in the perinatal context. Several mothers believed social workers, in particular, seemed to lack knowledge of mental health and experience of working with people like themselves. This left mothers feeling misunderstood and frustrated.

In some cases, mothers also commented that nonperinatal mental health practitioners were not always able to deal with the combination of a personality disorder diagnosis and a new baby. For example, one mother (Mother 4) had valued support from a complex needs team, but said the service normally discharged women if they became pregnant. Another mother who also valued support from a specialist personality disorder service nevertheless found it hard to attend the service's intensive group therapy while pregnant and after giving birth.

There was like a pressure to do well and to keep attending no matter, you know, how much you didn't... how ill you felt or how tired.... [Having a baby] definitely sort of has made it more difficult, you know.... There were older mums so they, you know, some of them have kids my age so they could definitely give us advice, so that did help. But none of them were new mums. (Mother 8)

Mothers Value Support to Cope With Their Struggles in Motherhood. Many mothers valued support to cope with motherhood and their mothering role in the context of their difficulties. Several women commented on how hard it had been arriving home from hospital after the birth and having to look after their babies, often largely alone.

All of a sudden, you're left with a baby. There you go. Here's his milk. This is the medication he's on. This is what you've got to do. There, go on. (Mother 8)

When mothers did receive support from specialist perinatal mental health teams and parent-infant services, they often found this particularly helpful. Some mothers described difficult relationships with their own parents; these women said they had not witnessed good-quality parenting themselves and therefore valued specialist support because it helped them believe they could be effective parents. They reported that this support increased their confidence in their abilities as a mother, reassured them even when they had difficult feelings toward their babies, and helped them strengthen their bond with their 
infants. Some mothers felt it took a long time for professionals to recognize that they needed help, not only their babies.

I was like. well, I haven't been parented myself so I don't know how to parent.... I found [the parent-infant team support] quite helpful because where my mum wasn't really a communicator, verbally-like, ways to talk to your children, or even like, hug them, because I struggle to hug them after they get to a certain age.... Because I don't remember ever having it myself. And so it helped me there, little things I could do or say. (Mother 3)

The one mother who stayed in a MBU also valued the support with mothering that she received there, and seemed to appreciate being looked after herself.

[The MBU] was a very, very good move.... I really didn't know what to do with the baby. And the head, the state it was in at that time, you know, it was just good to, you know-somebody was calling me to eat food, somebody was looking after us, if there were any problems with [my baby], there was somebody there to keep an eye on him. (Mother 4)

By contrast, mothers who had been admitted to acute psychiatric wards away from their babies felt that this separation exacerbated difficulties in bonding with them, especially where inflexible visiting arrangements made it difficult for them to spend time with their babies. Some mothers said they would have preferred to go to a MBU so that they could be with their babies.

[The ward] didn't really adapt to me whatsoever. They didn't. It was me having to say, "Look, I really need to go and see [my baby] today." And there wasn't really much acknowledgment there.... He has very set routines. So when we did finally have the time with him, it wouldn't fit in with his routine that he already had. So I felt like I was missing out a lot with him. (Mother 10)

More broadly, women also wanted support with the wider challenges they faced in the community as mothers, such as homelessness, poverty, and relationship breakdown; they often felt that these broader issues were not properly addressed.

When a person has gone over the place where they're considering suicide, giving them a pill is not going to take that away.... When they're back in their rational thinking, they're at it again, trying to commit suicide, so it just didn't make any sense. ... I was thinking, you're not just going to keep us here babysitting us with pills.... And that's not helping the situation at all. (Mother 9)

Valuing Professional Relationships Resembling Real-Life Friendships. Despite the difficulties outlined above, most mothers formed trusting relationships with 
some professionals. In some cases, these relationships took time to develop, whereas in other cases, mothers saw trustworthiness as a quality inherent in some (but not other) staff. Mothers particularly valued it when-rather than judging them to be unfit mothers or treating them as volatile and dangerousprofessionals showed that they understood mothers and were not alarmed by them.

[The specialist mental health midwife] doesn't judge.... You can talk to her about anything and it doesn't shock her.... Sometimes if you can't talk about some things, she already knows ... you know, that you're struggling with it or what you're thinking, what you're feeling. (Mother 8)

Several mothers described "fitting" or being "compatible" with professionals, and mothers also commonly described those they found supportive as being like a friend.

I find [my health visitor] more like a friend who kind of just gives you that bit of extra push that you need sometimes. (Mother 3)

I do trust [my perinatal psychologist] because I built up that relationship well where I can trust her. So she will give me like guidance in certain things.... The fact that I've not felt that she's spoken down to me. The fact that I feel she sort of understands what I'm saying and where I'm coming from. The fact that I can talk to her pretty much about anything.... You can have that, obviously not friendship, but it's like that vibe of a friendship sort of there. (Mother 7)

Some mothers particularly valued staff members they saw as maternal figures. This may reflect the fact that these women often felt they had not been parented well themselves and liked seeing parenting skills modeled to them, as well as feeling "mothered" themselves by professionals.

[The parent-infant therapist] is very motherly, I think she's, she's everything that I would picture a proper mother to be actually. That's probably the best way to describe her... nice, calm, loving, just so soft-natured.... I never had a great relationship with my mother, and I was in foster care for a while, so yeah, she is everything that I would probably picture a mother to be. (Mother 6)

Some mothers stated that they valued working with the same person over time. This consistency of support seemed to encourage the development of trust between mothers and staff. This consistency of support also related to how available mothers felt that staff were. Mothers valued staff who seemed to make an effort to make time for them and who were easily reachable on the phone. This seemed to indicate to them that staff were willing to go beyond the remit of their job. This perceived availability related to feeling like staff genuinely cared about and respected them, which seemed particularly 
important given that the majority of the women had limited support from their social networks and complex social environments.

It's fantastic, I mean, I go there every Tuesday lunchtime. [The general practitioner] gives up her lunch hour to speak to me, like a psychiatrist. So that's really nice. (Mother 6)

I laughed at [the perinatal mental health nurse] for [giving me] her mobile phone number, like it's very rare.... Like, I've never had a psychologist who had a mobile phone.... But she had a mobile phone. And I don't think that I've ever misused it. And, yes, I found it really helpful. (Mother 2)

\section{DISCUSSION}

This study is the first to explore experiences of services among perinatal women with a self-reported diagnosis of personality disorder. Mothers in our study often described living in challenging social circumstances. They reported difficulties getting services to listen to them and provide the support they needed; felt professionals struggled with the complexity of their needs, particularly in the context of a new baby; and sometimes even experienced professional intervention as worsening their mental health. These experiences may be partly the result of complex dynamics between perinatal women with high support needs and stretched services. However, some mothers also said they felt stigmatized by professionals. They felt judged automatically to be unfit mothers based on their diagnosis and described feeling caught in Catch-22 scenarios where they were "damned if you do, damned if you don't." These findings echo those of Wilson et al. (2018), whose study of mothers (of 3- to 11-year-olds) assessed to be affected by personality disorder found that women similarly described feeling "unheard," stigmatized as "bad parents," and felt their parenting struggles were not taken seriously by professionals. They are also in line with broader findings that clinicians may judge people with personality disorder diagnoses less positively than those with other diagnoses (Lewis \& Appleby, 1988; Markham \& Trower, 2010), while people diagnosed with personality disorders say health care professionals hold negative stereotypes about them and tend to discriminate against them or exclude them from services (Bonnington \& Rose, 2014; Rogers \& Dunne, 2011). Issues around stigmatization and perceptions of this diagnosis may be particularly salient in the perinatal context, where professionals' concerns around risk may be heightened because of young babies' vulnerability (indeed, a high proportion of women in our study had significant social services interventions). Overall, our findings, although based on a small sample and therefore difficult to generalize, may lend support to previous research that has highlighted the need to ask questions about the prevalence, use, and consequences of applying a personality disorder diagnosis to mothers (Stanley \& Penhale, 1999).

Despite the difficulties women described in their interactions with professionals, some mothers in our study nevertheless appeared to value specialist 
support from parent-infant teams and specialist perinatal services. This seemed especially important for women who felt they had not themselves been parented in a way that met their needs. It has been argued that parenting support that addresses parent-infant attachment and emotion regulation is particularly important for mothers with personality disorder diagnoses to prevent the intergenerational transmission of parenting and bonding difficulties and to help reduce the likelihood of repeated cycles of emotional abuse and neglect (Daum \& Labuschagne, 2018; Eyden et al., 2016). For mothers in our study who stayed in in-patient services, MBUs were preferred over acute psychiatric wards, where separation of a mother from her child was described as exacerbating difficulties with bonding in some cases. Beyond this, mothers also wanted support that addressed the wider social challenges they faced, such as homelessness, relationship breakdown, and poverty, as well as trauma.

Finally, we found that mothers formed trusting relationships with some professionals. They particularly valued relationships with professionals that resembled real-life friendships, and where professionals made themselves readily available. It may be particularly important for mothers diagnosed with a personality disorder to form trusting relationships with professionals due to their likelihood of social isolation, single parenthood, and difficult social circumstances (Wilson et al., 2018).

\section{LIMITATIONS AND FUTURE RESEARCH NEEDS}

Although this study addresses a clear gap in the literature, there are some important limitations. The sample was small, which limits the generalizability of our findings. Furthermore, over half of the women in our sample were White British and a large proportion were from London. The study may have benefited from a larger, more diverse sample so that a broader range of experiences could be explored. We did not independently confirm the diagnoses of women in our study, who self-reported having a diagnosis of a personality disorder.

Because the women were recruited through clinicians, we were not able to explore the experiences of women who were not in contact with any mental health services or women who did not accept or were not aware of their personality disorder diagnosis. These women may have important insights into the barriers that prevented them from receiving support. Recruitment via clinical mental health teams could also have risked overrepresenting women who were more engaged with services. While comorbid diagnoses are common with personality disorder diagnoses, it is not possible from our study to determine the impact of any additional mental health difficulties that women in our sample self-reported, and how this may have impacted their experiences or outcomes of mental health support. Future research may wish to consider how the presence of additional mental health difficulties might impact women with a personality disorder.

This study may also have benefited from gaining a wider perspective on this complex topic. Additional interviews could have been conducted with professionals and other stakeholders to consider their views, including the challenges that professionals face in providing adequate support for mothers diagnosed with a personality disorder. 


\section{CLINICAL IMPLICATIONS}

As outlined, our findings raise important questions about the use and implications of a personality disorder diagnosis in the perinatal period. There is a need for further consideration to be given to the way in which this diagnosis is experienced in this context and the possibility that it may serve to perpetuate discrimination against women, with consequences including social services involvement, lack of access to services, and increased pressures on women's mental health.

There is clearly also a need to give more consideration to how best to provide support to this group of women in a way that helps them feel heard and understood, and able to talk openly about their mental health without fear of negative repercussions. Early intervention appears to be important, and clinicians and service providers may benefit from psychoeducation on personality disorders during the perinatal period to address some of the concerns that mothers in our sample raised in terms of how they felt mental health professionals viewed and treated them. Our findings suggest that specialist perinatal and parent-infant services may be acceptable to some women diagnosed with a personality disorder who access support during the perinatal period. These findings could be made available to general practitioners and other professionals to highlight the potential value in referring women to these specialist services. There is some evidence to suggest that parent-infant psychology may be particularly promising for improving infant attachment security in high-risk families (Barlow, Bennett, Midgley, Larkin, \& Wei, 2015), and that a higher proportion of children are able to stay in the family home when mothers receive intense trauma-informed support (McPherson et al., 2018). Further research is needed to explore in more detail experiences and effectiveness of interventions that support parenting and the mother-infant relationship in women with complex and intersecting needs.

Finally, greater attention should be given to understanding and addressing the impact of mothers' broader social contexts. As outlined, women in our study often came from adverse backgrounds and faced considerable difficulties, including (among others) substance misuse, deprivation, relationship breakdown, trauma, and depression. There is a need to consider how these wider contexts intersect with and influence mothers' experiences of parenting and their treatment by services.

\section{REFERENCES}

Aviram, R. B., Brodsky, B. S., \& Stanley, B. (2006). Borderline personality disorder, stigma, and treatment implications. Harvard Review of Psychiatry, 14, 249-256.

Barlow, J., Bennett, C., Midgley, N., Larkin, S. K., \& Wei, Y. (2015). Parent-infant psychotherapy for improving parental and infant mental health. Cochrane Database of Systematic Reviews, 2015(1), CD010534.
Bonnington, O., \& Rose, D. (2014). Exploring stigmatisation among people diagnosed with either bipolar disorder or borderline personality disorder: A critical realist analysis. Social Science \& Medicine, 123, 7-17.

Börjesson, K., Ruppert, S., \& Bågedahl-Strindlund, M. (2005). A longitudinal study of psychiatric symptoms in primiparous women: Relation to personality disorders 
and sociodemographic factors. Archives of Women's Mental Health, 8, 232-242.

Braun, V., \& Clarke, V. (2006). Using thematic analysis in psychology. Qualitative Research in Psychology, 3, 77-101.

Brockington, I. (2004). Postpartum psychiatric disorders. The Lancet, 363(9405), 303-310. https:// doi.org/10.1016/ S0140-6736(03)15390-1

Coid, J., Yang, M., Tyrer, P., Roberts, A., \& Ullrich, S. (2006). Prevalence and correlates of personality disorder in Great Britain. British Journal of Psychiatry, 188, 423-431.

Conroy, S., Pariante, C. M., Marks, M. N., Davies, H. A., Farrelly, S., Schacht, R., \& Moran, P. (2012). Maternal psychopathology and infant development at 18 months: The impact of maternal personality disorder and depression. Journal of the American Academy of Child and Adolescent Psychiatry, 51, 51-61.

Crowley, G., Molyneaux, E., Nath, S., Trevillion, K., Moran, P., \& Howard, L. M. (2020). Disordered personality traits and psychiatric morbidity in pregnancy: A population-based study. Archives of Women's Mental Health, 23, 43-52.

Daum, M., \& Labuschagne, N. (2018). The early years parenting unit: An integrated approach to working with parents with complex trauma and their children under five. Clinical Psychology Forum, (312), 14-19.

Eyden, J., Winsper, C., Wolke, D., Broome, M. R., \& MacCallum, F. (2016). A systematic review of the parenting and outcomes experienced by offspring of mothers with borderline personality pathology: Potential mechanisms and clinical implications. Clinical Psychology Review, 47, 85-105.

Forman, J., \& Damschroder, L. (2007). Qualitative content analysis. In L. Jacoby \& L. A. Siminoff (Eds.), Empirical methods for bioethics: A primer (pp. 39-62). Oxford, UK: JAI Press.

Guest, G., Bunce, A., \& Johnson, L. (2006). How many interviews are enough? An experiment with data saturation and variability. Field Methods, 18(1), 59-82.

Howard, L. M., Molyneaux, E., Dennis, C. L., Rochat, T., Stein, A., \& Milgrom, J. (2014). Non-psychotic mental disorders in the perinatal period. The Lancet, 384(9956), 1775-1788.

Jinks, M., McMurran, M., \& Huband, N. (2012). Engaging clients with personality disorder in treatment. Mental Health Review Journal, 17, 139-144.

Kim, Y.-R., \& Tyrer, P. (2010). Controversies surrounding classification of personality disorder. Psychiatry Investigation, 7(1), 1-8.

Kulkarni, J. (2017). Complex PTSD-A better description for borderline personality disorder? Australasian Psychiatry, 25(4), 333-335.
Lewis, G., \& Appleby, L. (1988). Personality disorder: The patients psychiatrists dislike. British Journal of Psychiatry, 153, 44-49.

Markham, D., \& Trower, P. (2010). The effects of the psychiatric label 'borderline personality disorder' on nursing staff's perceptions and causal attributions for challenging behaviours. British Journal of Clinical Psychology, 42, 243-256.

McPherson, S., Andrews, L., Taggart, D., Cox, P., Pratt, R., Smith, V., \& Thandi, J. (2018). Evaluating integrative services in edge-ofcare work. Journal of Social Welfare and Family Law, 40, 299-320.

Newman, L. K., Stevenson, C. S., Bergman, L. R., \& Boyce, P. (2007). Borderline personality disorder, mother-infant interaction and parenting perceptions: Preliminary findings. Australian and New Zealand Journal of Psychiatry, 41, 598-605.

Newton-Howes, G., Weaver, T., \& Tyrer, P. (2008). Attitudes of staff towards patients with personality disorder in community mental health teams. Australian \& New Zealand Journal of Psychiatry, 42, 572-577.

NHS England. (2019). NHS England Long Term Plan. Retrieved from https://www.longtermplan .nhs.uk/

Petfield, L., Startup, H., Droscher, H., \& CartwrightHatton, S. (2015). Parenting in mothers with borderline personality disorder and impact on child outcomes. Evidence Based Mental Health, 18, 67-75.

Rogers, B., \& Dunne, E. (2011). 'They told me I had this personality disorder... All of a sudden I was wasting their time': Personality disorder and the inpatient experience. Journal of Mental Health, 20, 226-233.

Russell, K.,Ashley, A., Chan, G., Gibson, G., \& Jones, R. (2017). Maternal mental health-Women's voices. Retrieved from https://www.rcog .org.uk/globalassets/documents/patients/ information/maternalmental-healthwomens -voices.pdf

Stanley, N., \& Penhale, B. (1999). The mental health problems of mothers experiencing the child protection system: Identifying needs and appropriate responses. Child Abuse Review, 8(1), 34-45.

Stein, A., Pearson, R. M., Goodman, S. H., Rapa, E., Rahman, A., McCallum, M., ... Pariante, C. M. (2014). Effects of perinatal mental disorders on the fetus and child. The Lancet, 384(9956), 1800-1819.

Wilson, R., Weaver, T., Michelson, D., \& Day, C. (2018). Experiences of parenting and clinical intervention for mothers affected by personality disorder: A pilot qualitative study combining parent and clinician perspectives. BMC Psychiatry, 18(1), 152. 